\title{
A new stope reconciliation approach
}

\author{
B McFadyen Université Laval, Canada \\ KR Woodward Australian Centre for Geomechanics, The University of Western Australia, Australia \\ Y Potvin Australian Centre for Geomechanics, The University of Western Australia, Australia
}

M Grenon Université Laval, Canada

\begin{abstract}
Open stope mining remains the most widely used method for the underground extraction of hard rock metalliferous deposits since mines became increasingly mechanised from the early 1980s. One of the most significant factors that influence the value creation and profitability of open stope mining is linked to the ability of the mining process to accurately extract a designed stope. The performance of a stope is quantified during a reconciliation of the achieved excavation with respect to a planned geometry. Deviations from a planned stope volume can be categorised as material unintentionally mined (overbreak) or material intended to be mined but not recovered (underbreak). Conceptually, minimisation of both cases is important to mine economics as overbreak represents extra costs of mining waste while underbreak represents lost value from the sterilisation of ore.

This paper describes a new approach for stope reconciliation that facilitates the identification of the root causes of overbreak and underbreak at three progressively finer levels of detail. This is achieved by quantifying stope performance with respect to the entire stope, individual stope faces and octree blocks.

The reconciliation of an entire stope volume is systematically performed at most open stope mines and is often complimented by the reconciliation by individual stope faces. The octree analysis is a novel stope reconciliation technique that subdivides stope volumes into small blocks (usually $<1 \mathrm{~m}$ ). The sparse grid structure of this analysis enables the investigation to understand the relationship between stope performance and multiple factors such as blasthole standoff distance, orientation and blasting energy, effective radius factor, distance to development, distance and orientation to faults, and distance to convex hull. Stope reconciliation on a per octree basis assesses the stope at a resolution where the variation of performance and influencing factors can be captured and investigated.
\end{abstract}

Keywords: stope design, stope reconciliation, overbreak, underbreak

\section{Introduction}

The vast majority of underground mines in Australia and Canada use some form of an open stope mining method. The profitability of open stope mining is intrinsically linked to the accuracy and execution of the stope design and mining process. The performance and value realised from mining a stope is significantly influenced by the amount of overbreak (OB) and underbreak (UB) achieved. The research focussed on the development of reconciliation methods which can quantify the causative factors which drive $O B$ and $U B$. The analysis allows for these factors to be accounted for when designing future stopes with the aim to minimise $O B$ and $U B$ and further maximise the value of open stope mining. This paper presents a new method for the reconciliation of open stopes and demonstrate the power of this new approach through a case study.

\section{Stope performance quantification}

In the industry, stope performance is currently quantified through reconciliation of the mined stope with the stope design and identifying OB and UB (Figure 1) (Potvin at el. 2016). The mined stope is captured using a cavity monitoring system (CMS) (Miller et al. 1992). For most mines, stope reconciliation is driven by project 
economics and focusses on quantifying performance on a per stope basis. Mines may also consider stope performance from a geotechnical perspective and reconcile stopes at a finer resolution. This typically involves quantifying stope performance on a per face basis, for example, with respect to the hanging wall (HW) of a stope. This research developed a third and finer level of resolution, quantifying stope performance on a per octree basis.

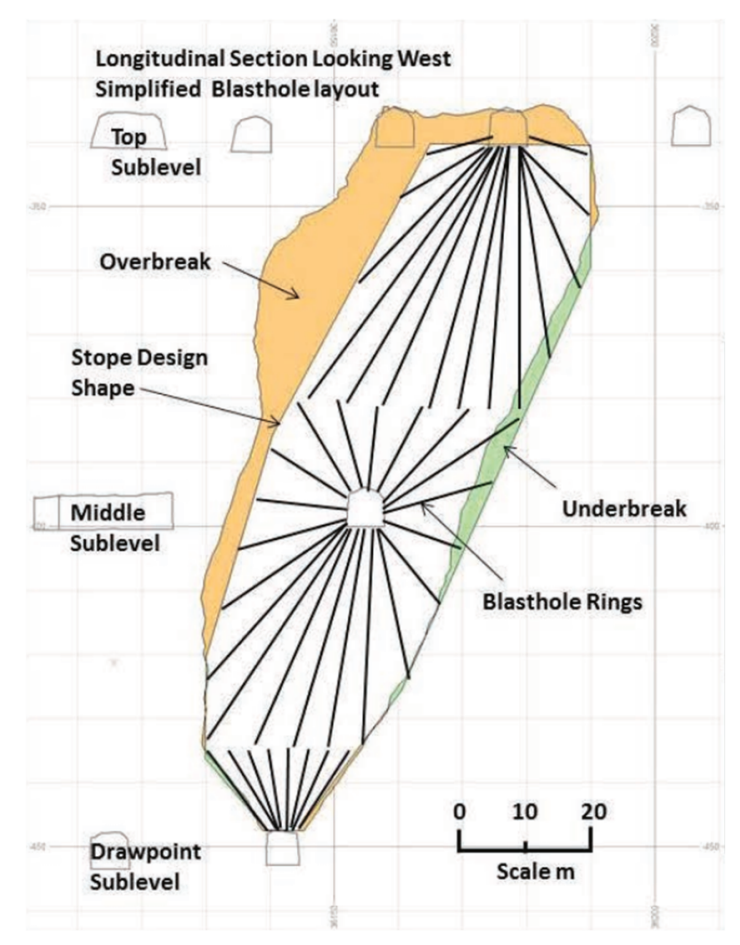

Figure 1 Illustration of stope overbreak and underbreak with respect to a sublevel stoping mining method (Potvin et al. 2016)

\subsection{Per stope}

Performance measures are averaged per stope and consider the total volume of rock mined and the total volume contained within the design surfaces. The volumes are used as derived measures such as an average overbreak (OB) percent or total underbreak (UB) per stope. Only a broad characterisation of influencing factors is possible, e.g. blast powder factor, mining method, or stand-up time. This characterisation is limited in resolution and to cases where it is reasonable to compare performance to an averaged characterisation for a stope. For example, it is unsound to compare the stope performance to geotechnical parameters if rock type greatly varies across the stope.

\subsection{Per face}

Performance measures are averaged per stope face and they must consider the mined and designed volumes. This implicitly requires the allocation of volumes to the face of a stope. The allocated volumes are used to derive average measures such as equivalent linear overbreak slough (ELOS) and equivalent linear lost ore (ELLO) proposed by Clark (1998) (Figure 2). The characterisation of influencing factors includes the geotechnical factors required in the Stability Chart (modified stability number, shape factor) as proposed by Mathews et al. (1981) and blasting factors (standoff and hole orientation). This is the typical resolution for most stope reconciliation assessments and stope designs. Depending on the mine, per face assessment may also consider the type and strength of any exposed backfill or the kinematic assessment of interactions between the stope face, rock mass and/or larger scale structures. 


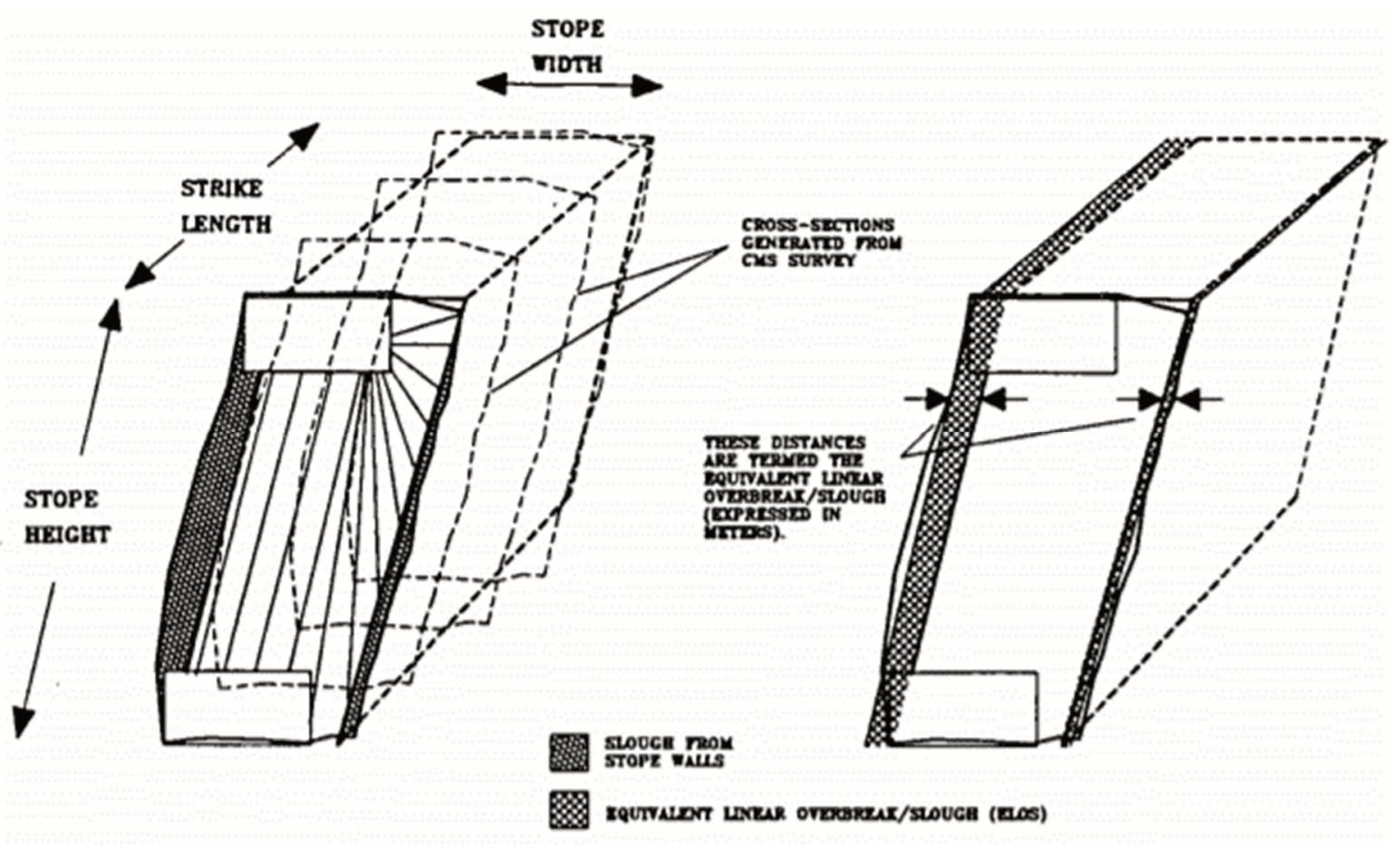

Figure 2 Illustration of equivalent linear overbreak slough (ELOS) (Clark 1998)

\subsection{Per octree}

Per octree analysis represents the new advancement in stope reconciliation and analysis by considering an even finer resolution. The performance of any given surface area of a stope design is quantified by calculating the distance in the direction normal to the design surface and a surface generated by a CMS (Figure 3 ). This measure of performance is referred to as the projected distance. Analysis on a per octree basis allows for the stope to be assessed at a resolution where the variation of performance and influencing factors can be captured (usually $<1 \mathrm{~m}$ ). Figure 4 illustrates how stope performance can dramatically vary across a stope face.

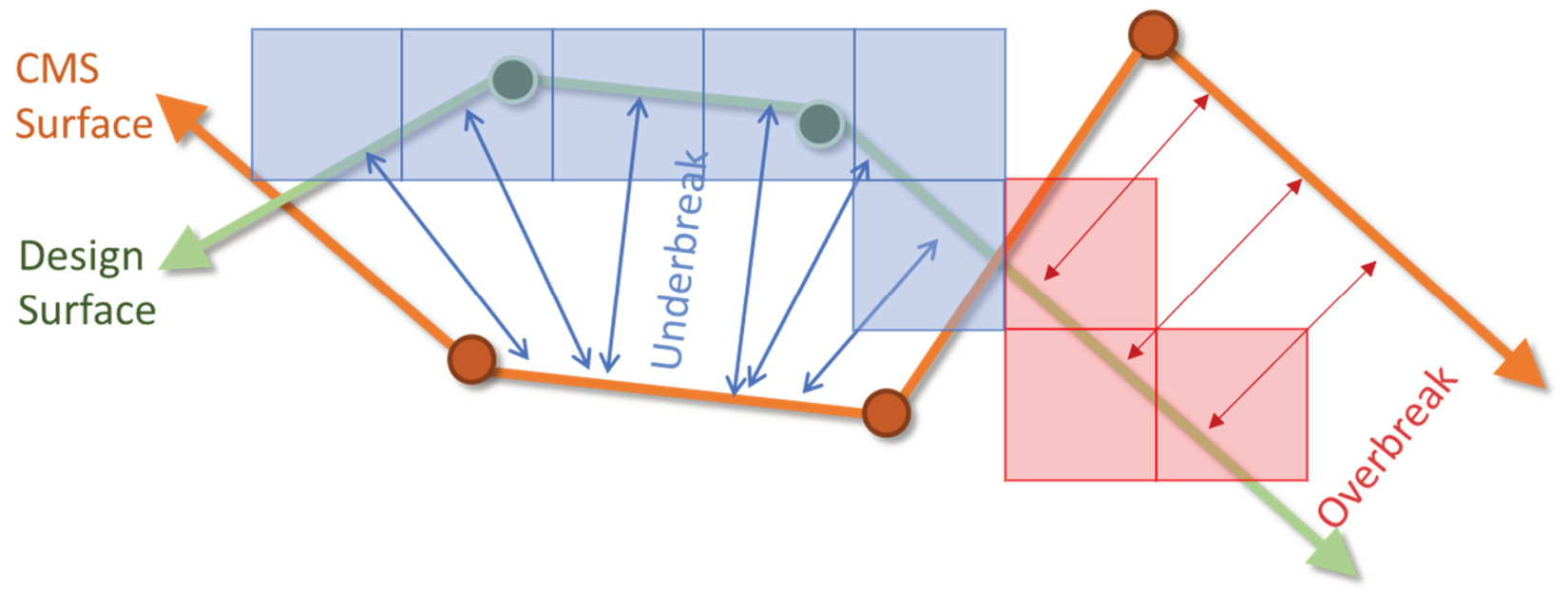

Figure 3 Illustration of octree stope performance quantified by calculating the distance in a direction normal to the design surface between the design surface and the cavity monitoring system (CMS) for each octree 


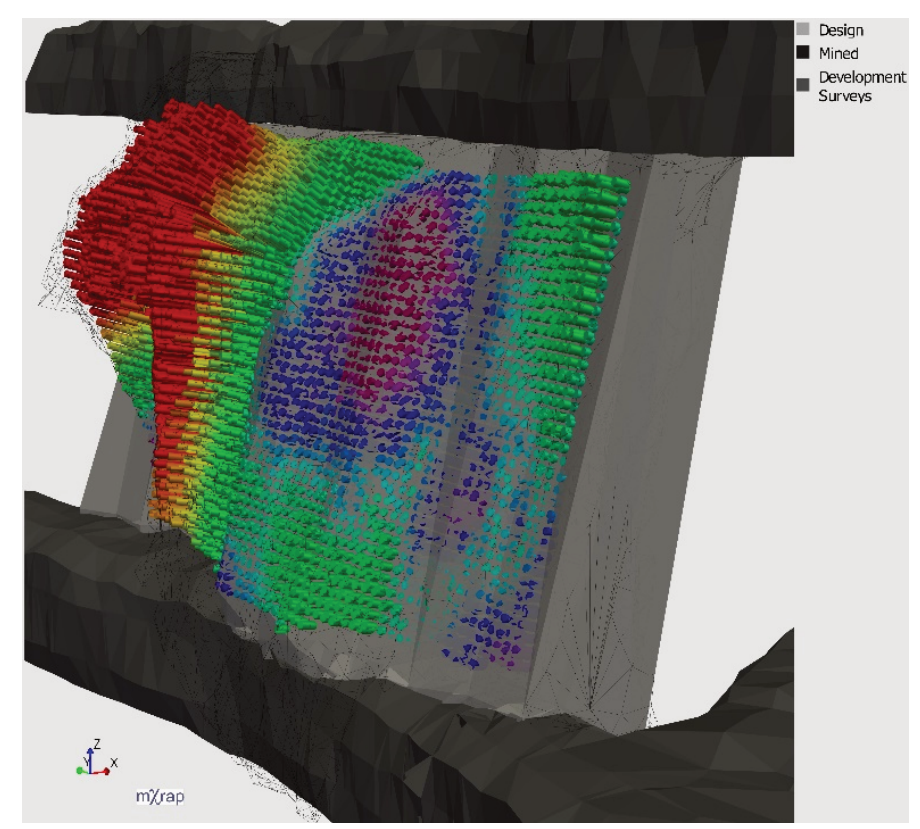

Figure 4 An example of how stope performance can dramatically vary across a stope face

The projected distance provides a measure of performance which can be compared to a local characterisation of stope design factors. Characterisation is flexible and considers the various sources of information available and relevant to a specific site. This typically includes data sources such as stope design surfaces, mined stope surface, drill strings for production blasting, geotechnical data, and geological data. The data is transformed into spatially referenced parameters and then allocated to the octree blocks generated on the stope design surface. The Appendix provides the concept, interpretation, and examples of parameters, which have been investigated to diagnose stope performance on an octree basis.

\section{$2.4 \quad$ Faces}

A fundamental part of analysis is the definition of stope faces. The motivation for explicitly defining stope faces is to achieve a convenient and consistent grouping of octree blocks that are influenced by similar critical factors. Additionally, a practical benefit is the ability to express stope reconciliation outcomes in the context of stope faces, e.g. improve blasting practices to recover the UB on the footwall (FW). The calculation occurs during the reconciliation process through an algorithm supervised by the user. A semi-automated process has several benefits over a completely manual process. In a practical sense, the most significant benefit is that the process is fast and, for most cases, also enables the consistent definition of stope faces. Individual faces are primarily defined from detected edges in the stope design shape. Detected faces can be various shapes and orientations along with cases where faces are domed/irregular.

Figure 5 illustrates the effective radius factor (ERF) for each individual stope face (Figure 5a). The chart plots the performance of each octree block intersecting the stope's design in terms of projected distance ( $y$-axis) and is compared to the blocks ERF with a moving average of the data ( $x$-axis). Moving averages are grouped by the octree's face type.

This chart shows that the two east walls (green) had an average projected distance of 0 and no correlation to ERF. This is in contrast with all other face types which show a strong correlation with ERF. The crown (variable type due to its domed nature) and the west wall have underbreak on average for all ERF values. The north and south walls have underbreak on average for ERF values up to 5, before experiencing overbreak. The south wall is the worst performer, having an average overbreak of $>1.5 \mathrm{~m}$ when ERF is $>11$. Given this behaviour is repeatedly observed and cannot be explained by other influences (e.g. blasting pattern), the practical outcome of this type of analysis may be to minimise high ERF cases when designing stopes or modify blasting practices. The consistent methodology of finding faces and quantifying stope performance with an 
octree-level of detail allows for correlations to be revisited to investigate whether changes to mining practices have improved stope performance.

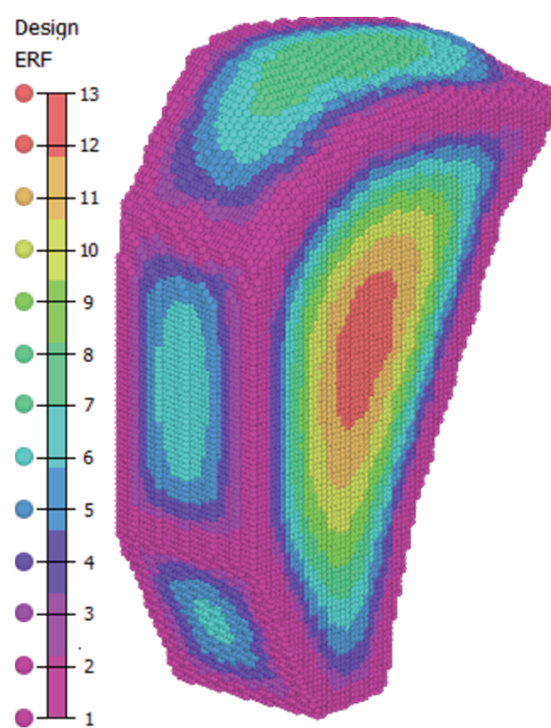

(a)

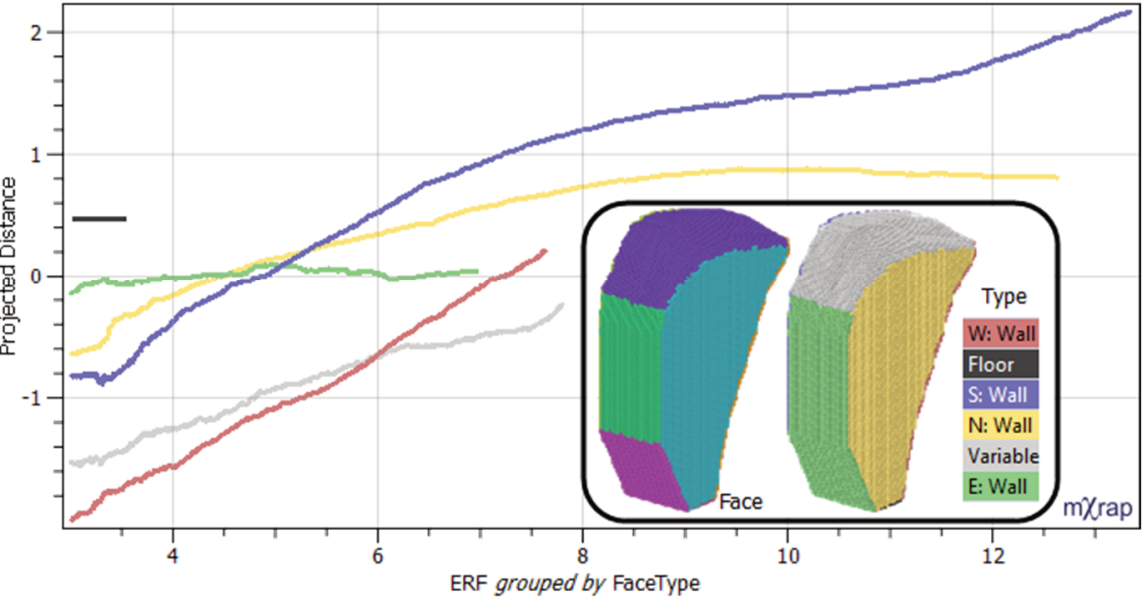

(b)

Figure 5 (a) 3D view of effective radius factor (ERF) calculated for individual faces and contoured on stope design; (b) Projected distance (y-axis) of each octree block intersecting the stope's design compared to an octree's ERF (x-axis). A moving average of the data is grouped by face type

\subsection{Investigation methodology}

The new approach to stope performance analysis is to first consider stope performance on a per stope and per face basis. This analysis focusses on parameters associated with the stope that may influence performance, e.g. mining sequence, stand-up time, mining depth, blasting pattern, etc. The performance analysis aims to identify parameters which are critical to face-specific performance and utilise face type classifications which are assigned during the reconciliation process. The results of this investigation are informative in themselves but also provide the basis for focusing of per octree analysis. This analysis often utilises the same face type classification, however, it allows for the influence of critical parameters to be quantified at a resolution that can capture the variation in stope performance.

The 'start to finish' analysis uses a series of applications within the $m$ Xrap software architecture. The result is a step-based linear process which focusses on reducing the time required for site-based mining engineers to process and analyse stope performance data and obtain valuable information about the root cause of $O B$ and UB that can be used for future stope. The software implementation of stope reconciliation aligns with the four-step research methodology used for the proceeding case study. This four-step method is:

1. Preparing the data

a. Building the necessary databases and surveys.

b. Quality check of the surveys.

2. Stope reconciliation

a. Reconciliation between the mined and design surveys.

i. Configuration of the stope faces.

ii. Calculation of stope performance and other parameters.

3. Stope performance analysis

a. Per stope analysis to assess OB \% and UB \% (e.g. cumulative chart). 
i. Use site-specific filters (e.g. primary versus secondary stopes) for identifying underperforming stopes.

b. Per face analysis

i. Identify underperforming faces using ELOS and ELLO.

ii. Identify critical parameters associated to underperforming stopes and faces.

c. Per octree analysis

i. Identify critical parameters associated to underperforming stopes and faces.

4. Consider Step 3 to develop a holistic comprehension of critical factors influencing stope performance.

\section{Case study}

This research was sponsored by seven mine sites. This paper presents some of the analysis and results from one of the sponsors, focussing on the basis of individual faces and octree analysis.

\subsection{Data overview}

This case study consists of 192 stopes that were reconciled and complied into a database which was used in the following analyses. Figure 6 illustrates these 192 stopes. This mine uses a primary-secondary stoping method, mining transversal stopes in a pyramidal sequence. Typical blasting follows a fanned drilling pattern.

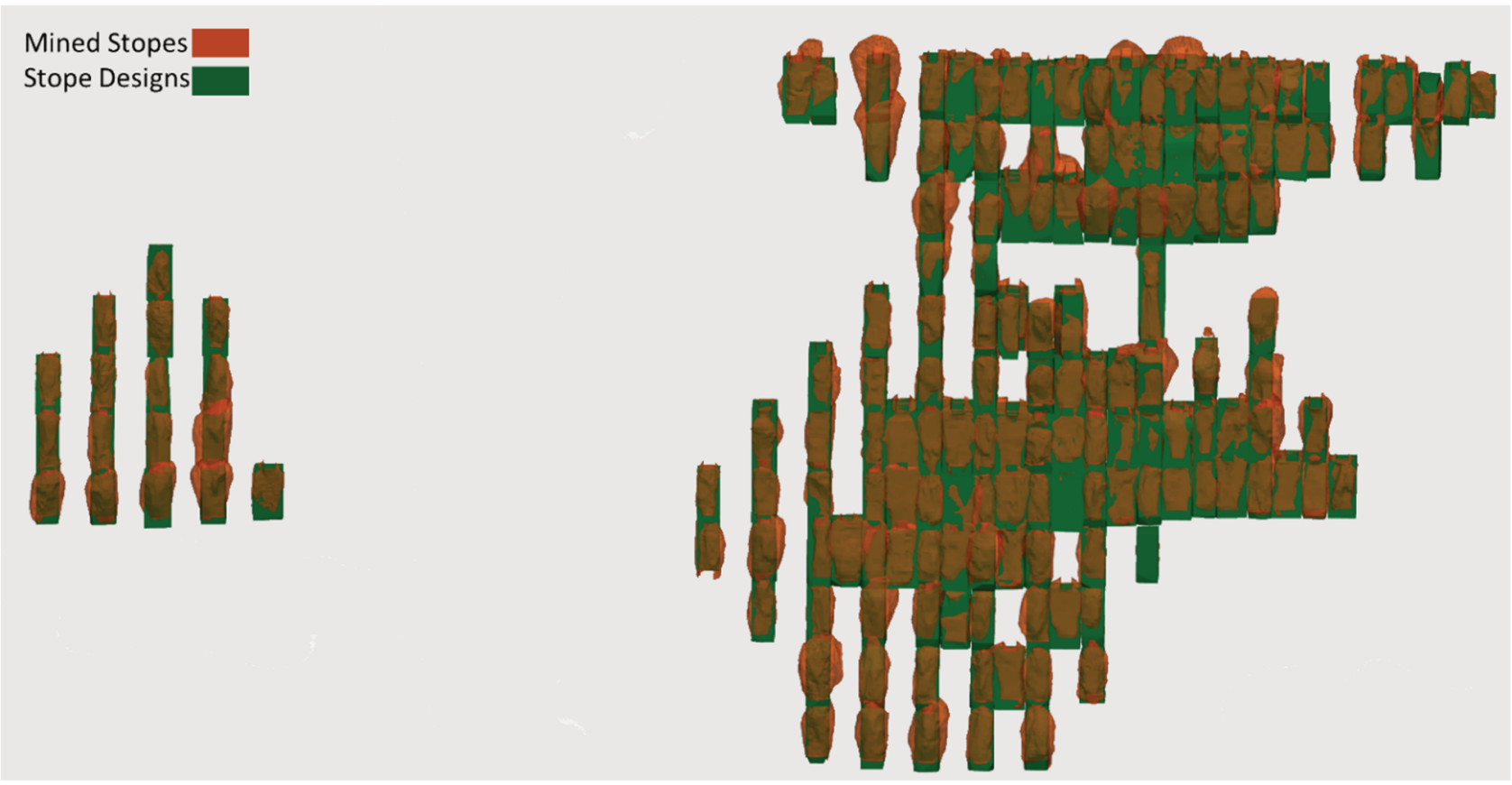

Figure 6 A section of the stoping area for the case study. The stope designs are shown as green surfaces and the cavity monitoring system shapes are orange

\subsection{Per face analysis results}

For the 192 stopes in the case study, Figure 7 plots cumulative distribution charts on a per face basis (ELOS in Figure 7a and ELLO in Figure 7b). This is an example of a simple database query to begin to understand the driving factors behind stope performance. Using a per face grouping, the main OB contributor is the HW and the main UB contributors are the side walls (west and east faces) and the floor. For all face type except the floor, the ELOS is greater than ELLO in absolute terms implying more OB being generated in the stopes than UB. 


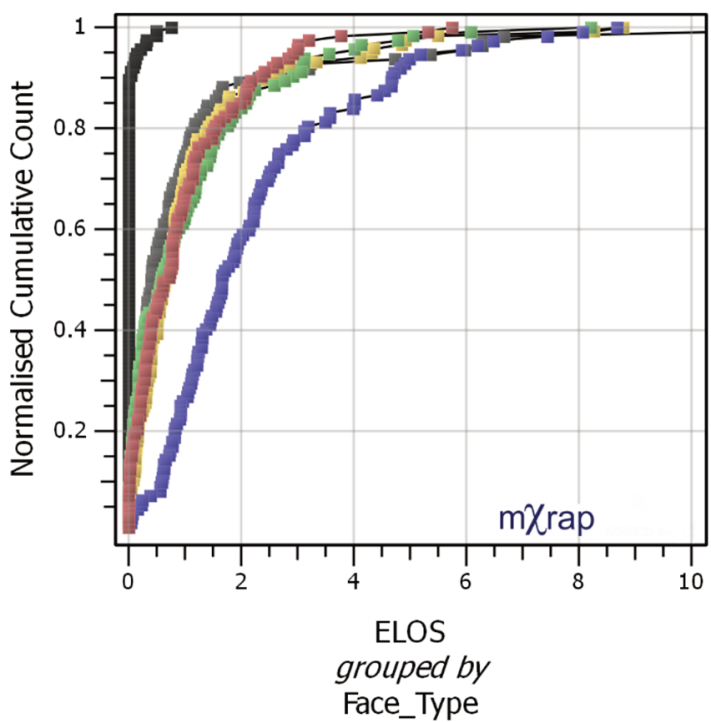

(a)

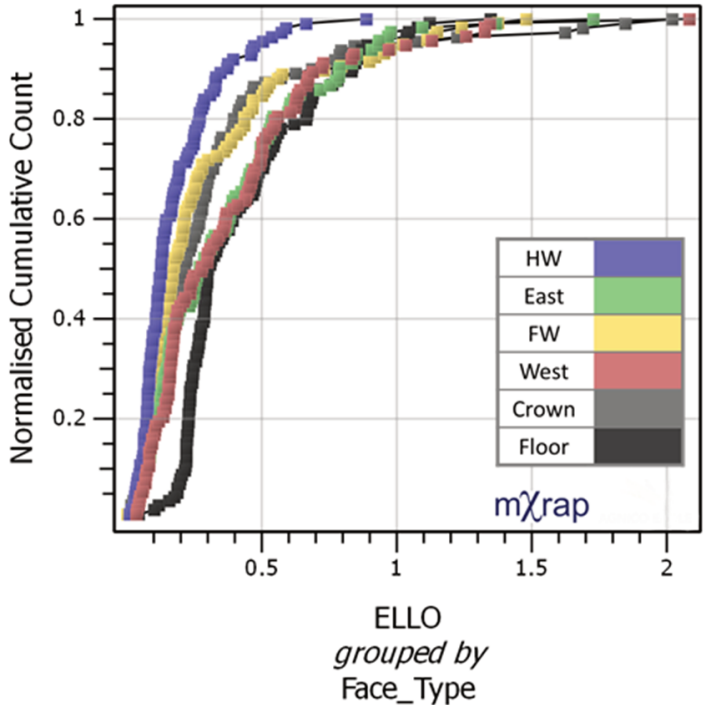

(b)

Figure 7 Cumulative distribution of the stope's performance using a face grouping. Note that not the same $X$-axis scale is used for better visualisation. (a) Equivalent linear overbreak slough (ELOS); (b) Equivalent linear lost ore (ELLO)

It is evident from the distributions in Figure 7 that the $\mathrm{HW}$ is the critical face for $\mathrm{OB}$. To further understand what factors influence HW performance, broad geotechnical properties can be investigated. The rock quality designation (RQD) was investigated for these stopes' HW face (Figure 8). An average RQD was taken over a $10 \mathrm{~m}$ wide zone for the HW. These charts show that while there is significant scatter in the results, there is a general trend for ELOS to increase with lower RQD values and ELLO to increase for larger RQD values. The correlations suggest that the width of low RQD zone likely influenced the ELOS in the HW.

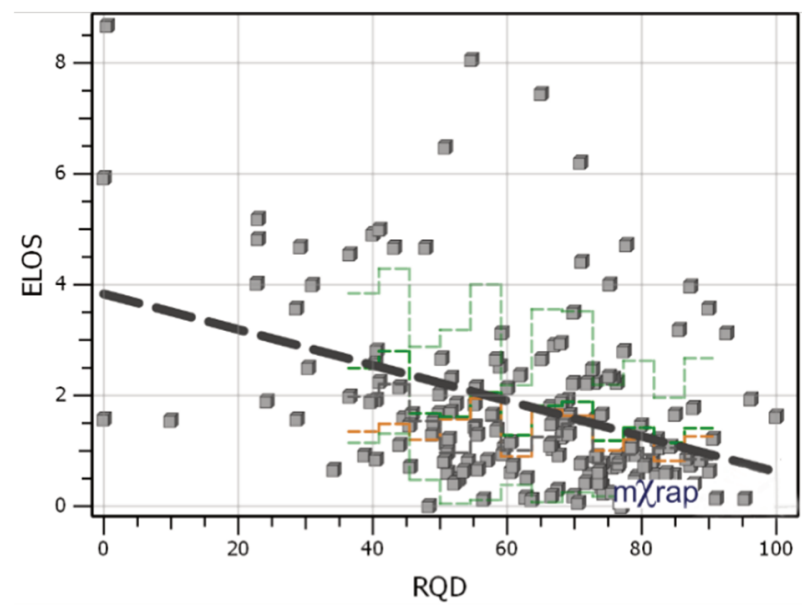

(a)

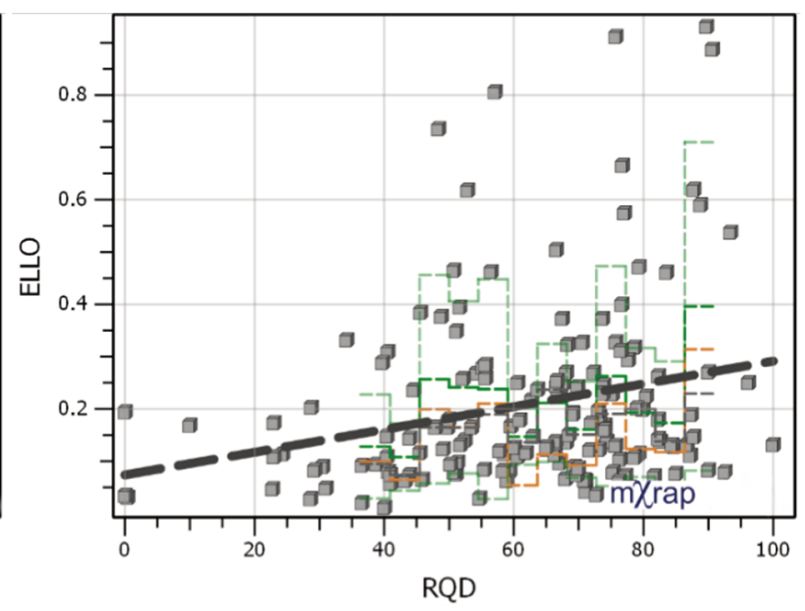

(b)

Figure 8 Hanging wall performance versus rock quality designation (RQD) considering only primary stopes. (a) Equivalent linear overbreak slough (ELOS); (b) Equivalent linear lost ore (ELLO)

\subsection{Per octree analysis results}

The following results focus on the stopes' HW performance, being the face identified as generating the most OB. The octree analysis can be presented using two kinds of charts. The first one consists of a stope face heat map. Chart consists of superposing stope faces for a selected face type (for example, only the HW faces). The values for the specific variable are then averaged based on their location and displayed as a heat map of that variable across the face. The second chart is a stope performance chart (Figure 9) and aims to identify trends 
based on the projected distance for the octree between the design surface and the mined surface, and the value of the specified variable for these octree block. The chart contains a moving average, identified by a black line, to help follow the trend in the data. Based on the trend, there can be a correlation to OB, a correlation to UB, or no correlation. Statistical analysis, in the form of notched box and whiskers plot, is overlayed in the chart to provide a measure of confidence when interpreting trends in the data.

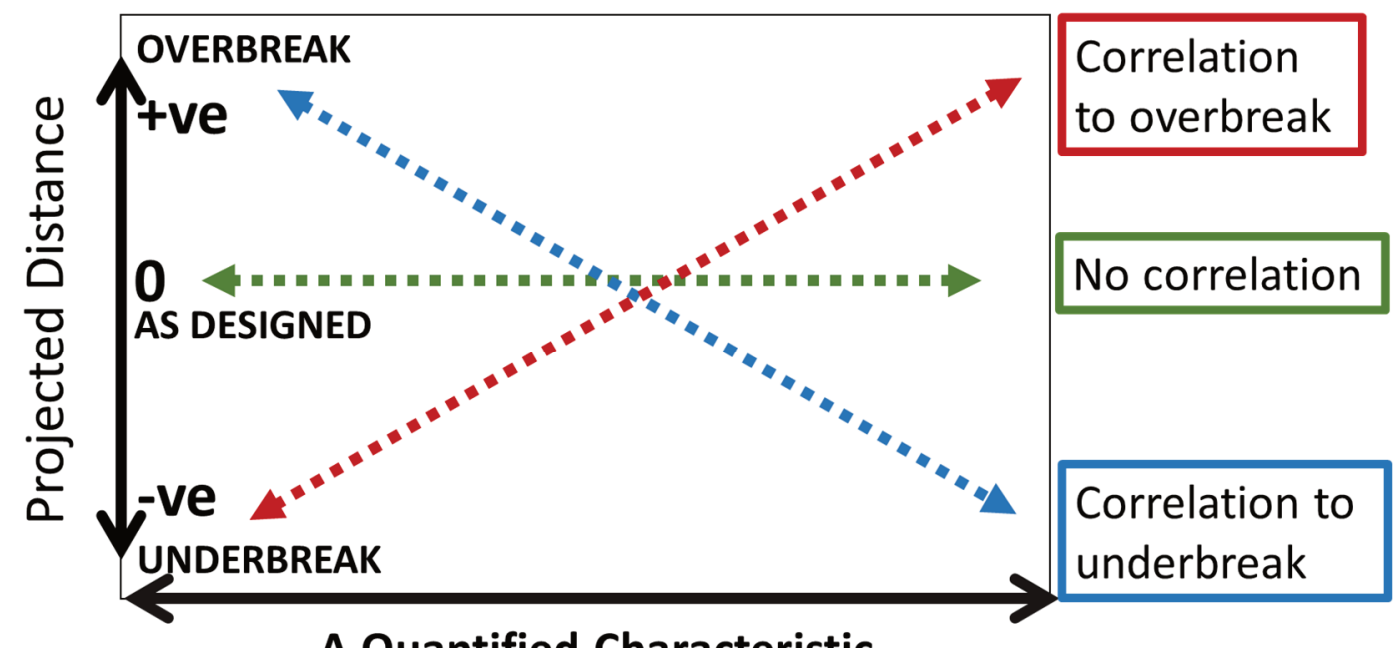

Figure 9 Stope performance chart based on octree analysis

\subsubsection{Average hanging wall performance}

A heatmap is generated for the average projected distance in the stopes' HW (Figure 10). This figure illustrates that, on average, the largest OB occurs in the top middle of the HW $(>2 \mathrm{~m})$ and largest UB occurs around the bottom edges $(<-2 \mathrm{~m})$.

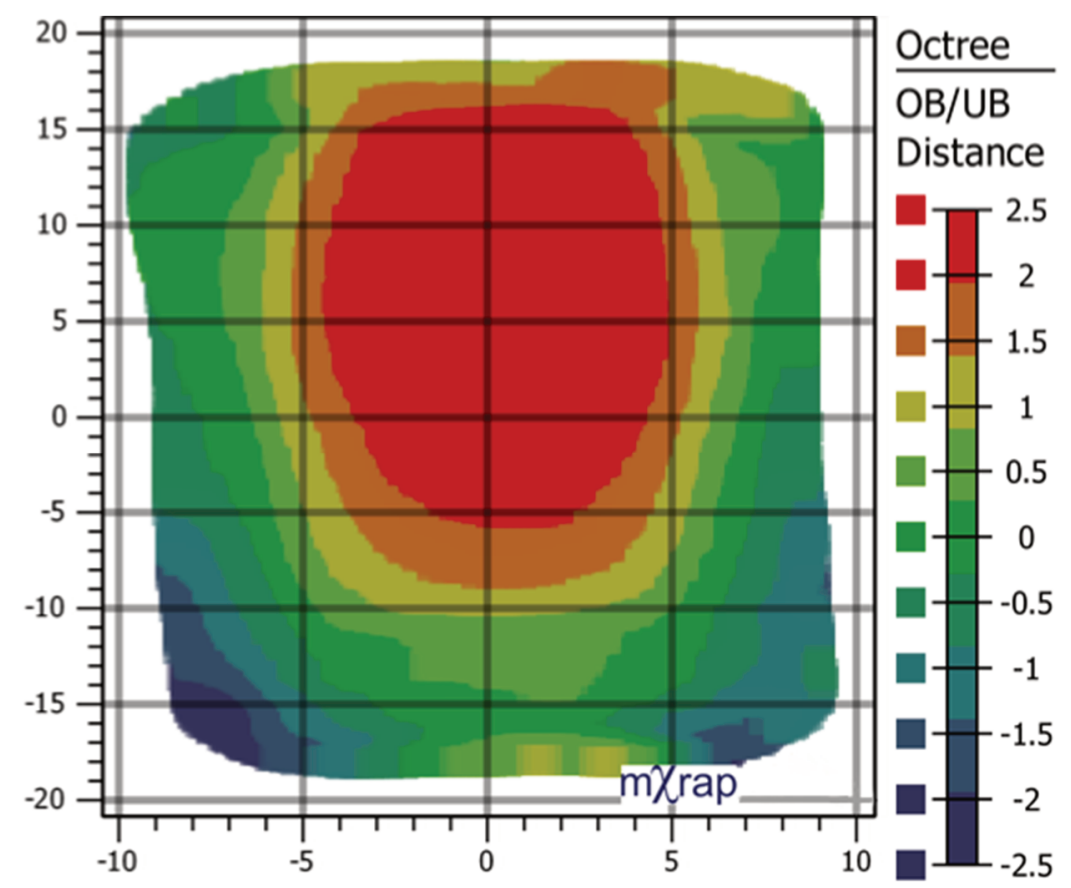

Figure 10 Hanging wall heat map of average projected distance 


\subsubsection{Effective radius factor}

The ERF can be used to quantify the localised stress condition and the bending moment of the excavated span. Larger ERF values are measured in the middle of the surface and the maximum ERF value will increase when the HW excavated span increases. The heatmap shown in Figure 11b shows the average ERF value for the HW faces. The positive correlation between the projected distance and the ERF (Figure 11a top) indicates that stope geometry influences the stope performance. While the largest $O B$ is generated in the middle of the HW and hence highest ERF, the degree of $O B$ is constantly correlated to ERF over the range of 0.5 to 4 essentially covering the entire face. Further analysis grouped stopes by mining level. Deeper stopes show the same correlations between the ERF and the projected distances, however, in comparison to shallower stopes, much more $O B(+1-2 \mathrm{~m})$ can be expected for similar ERF values. Red and orange colour curves represent the deepest stope horizons (Figure 11a bottom). This analysis suggests that HW performance of these stopes is not only related to the localised stress measured with the ERF but is also sensitive to stress increases as mining progresses deeper.
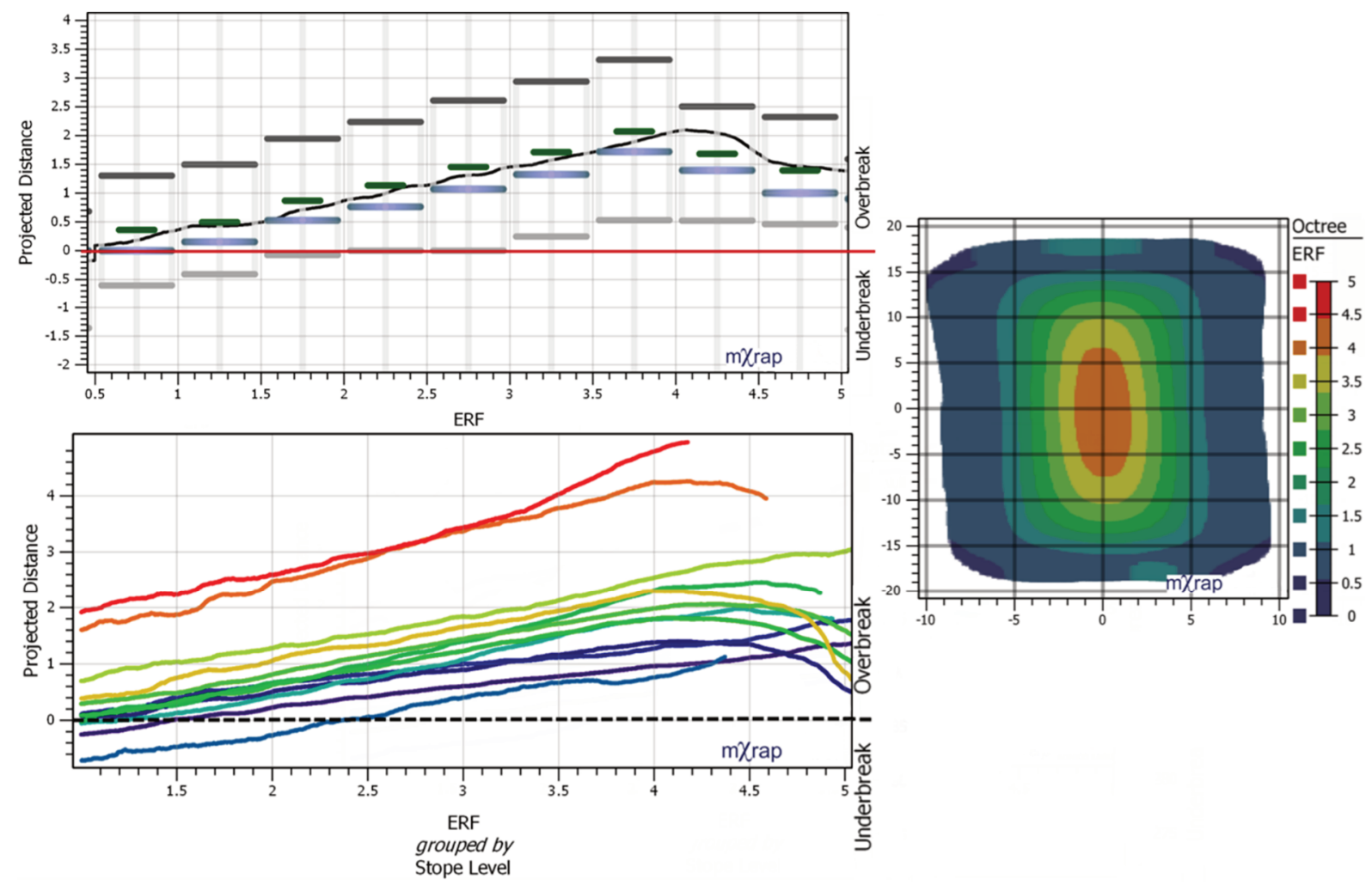

(a)

(b)

Figure 11 (a) A stope's hanging wall performance versus effective radius factor (ERF); (b) Average ERF heatmap for the hanging wall

\subsubsection{Blast energy proxy}

The blast energy proxy is a function of the borehole layout and can be used to evaluate blast-induced damage. The density of boreholes near the design surface influences the energy proxy value. The borehole design generates larger energy proxy values in the top middle of the HW (Figure 12b). This is related to the fact that fanned drilling is used and all the drill rings start from the middle. There is practically no energy in the bottom of the stopes because of sill outs (no drill rings). The positive correlation between the projected distance and the blast energy proxy (Figure 12a top) indicates that blasting influences the stope performance. The location of maximum energy fits with maximum OB values. Similarly, to the previous assessment of ERF, the difference in trends between the deeper stopes and the rest indicates that the performance of the HW, with regards to blasting, is sensitive to increased stress with depth. The deeper horizons are shown by the 
red and orange curves in the bottom graph in Figure 12a (bottom). This analysis shows that stope performance is likely influenced by a combination of ERF, blasting, and mining depth.

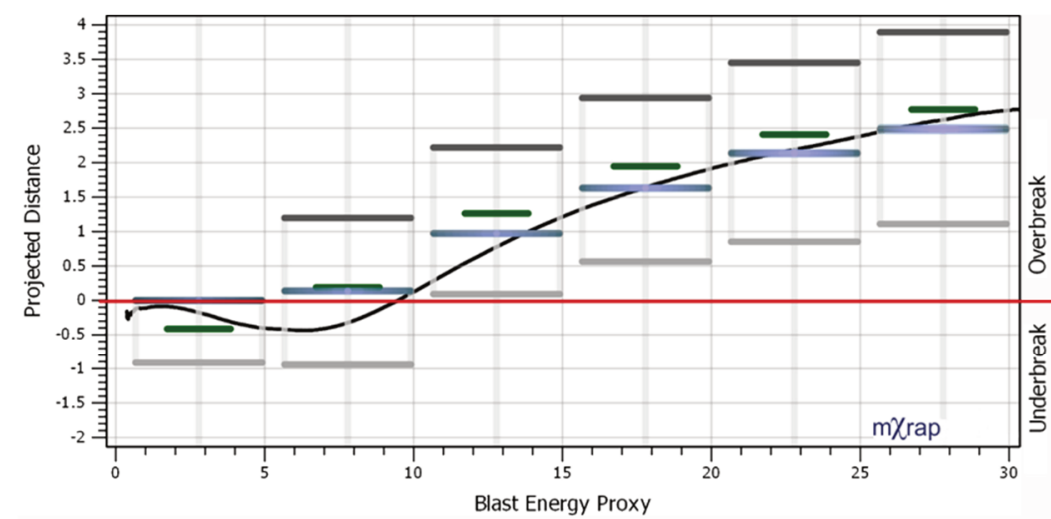

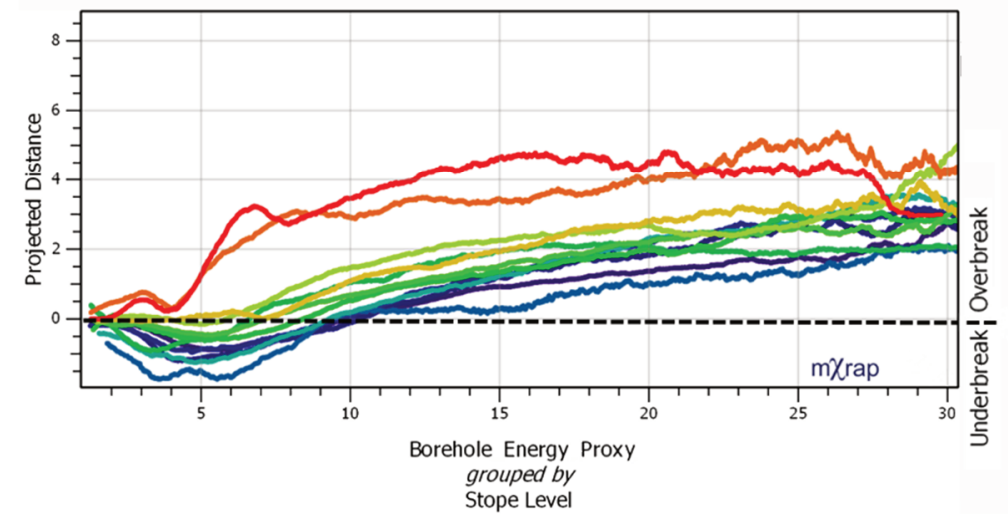

(a)

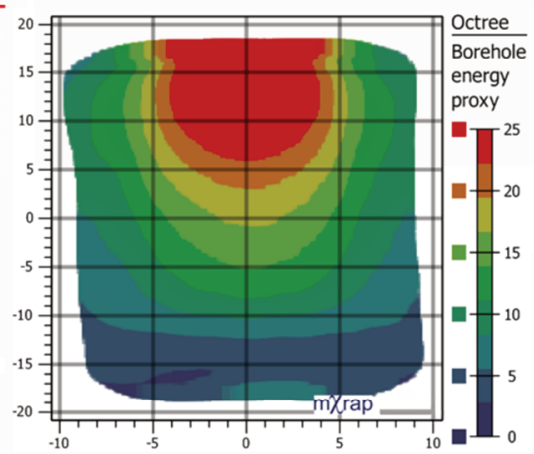

(b)

Figure 12 (a) Hanging wall stopes performance versus blast energy proxy; (b) Blast energy proxy heatmap for the hanging wall

\subsubsection{Borehole standoff distance}

The correlation between the borehole standoff distance and the projected distance reflects blast-induced damage and, in part, the depth in the impacted rock mass. Figure 13b shows the HW standoff heatmap and illustrates that the areas of large $\mathrm{OB}$ at the top of the HW occurs where the standoff distance is small $(<0.5 \mathrm{~m})$. Larger borehole standoff distance occurs in the corners and the bottom of the HW. Note that values above $3 \mathrm{~m}$ are due to the bottom development. The negative correlation between the projected distance and the borehole standoff distance indicates that blasting standoff influences the stope performance with the projected distance decreasing when the standoff distance increases (Figure 13a top). The overall best performance results ( $0 \mathrm{~m}$ projected distance) are obtained for standoff distance greater than $2 \mathrm{~m}$. Consistent with conclusions from the analysis, $\mathrm{OB}$ is significantly greater for deeper stopes. Deeper horizons are shown by the red and orange curves in the bottom graph in Figure 13a (bottom). In a practical sense, larger standoff distances may be required to reach a projected distance of 0 , i.e. the design surface matches the CMS. 


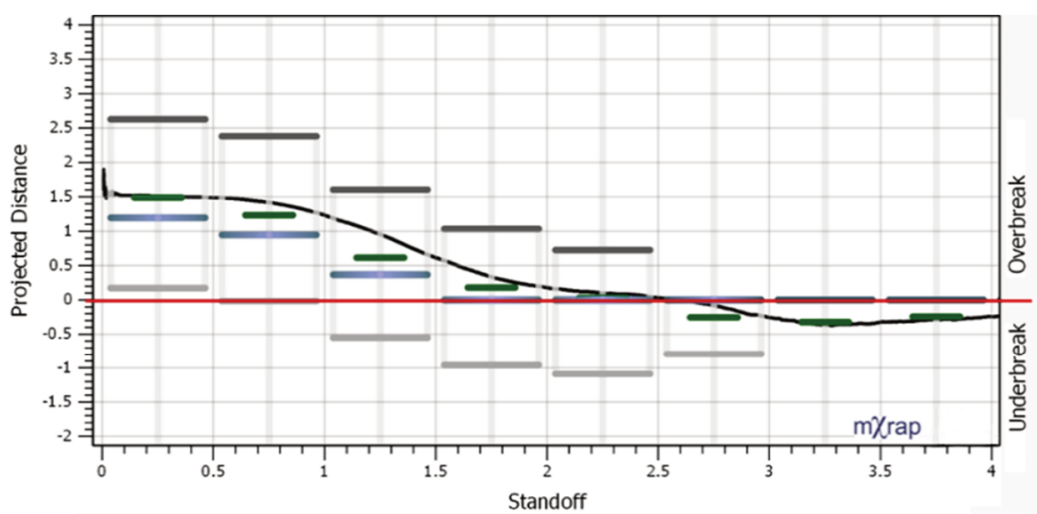

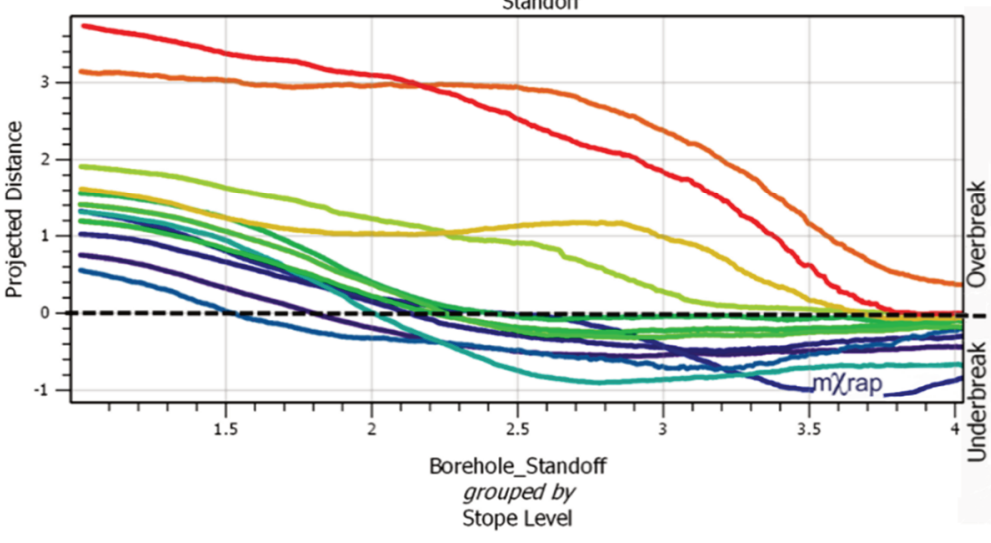

(a)

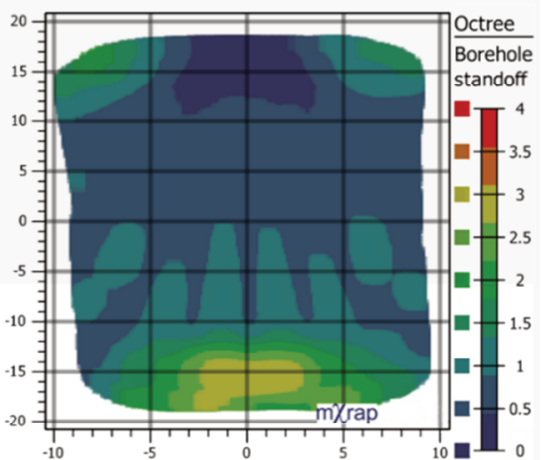

(b)

Figure 13 (a) Hanging wall performance versus borehole standoff distance; (b) Borehole standoff distance heatmap for the hanging wall

\subsection{Results discussion and summary}

Stope reconciliation and performance analysis was done for 192 mined stopes. OB and UB parameters were measured during the reconciliation process and used to characterise stope performance at three different levels of resolution and identify critical parameters influencing stope performance using the new method. The different parameters characterise the mining process, the drilling and blasting, the geometry, the geomechanical properties of the rock mass, and the geological structures. The analysis of stope performance was completed on a per face basis and on a finer level by looking at the performance per octree. Some of the findings are listed below based on what is presented in this paper.

1. Face performance:

a. Main contributor for $\mathrm{OB}$ is the HW.

b. Main contributor for UB are the side walls and the floor.

c. The critical parameter identified for the HW was RQD.

2. Octree performance:

a. Largest $\mathrm{OB}$ location within the HW is in the top middle of the face.

b. Largest UB location within the HW is in the bottom edges and corners.

c. Critical parameters identified for the HW were ERF, blast energy proxy and borehole standoff.

d. The depth of mining is correlated to OB performance in the HW.

Mining method is consistent throughout the reconciled stopes and has a strong influence on performance, with borehole energy proxy and borehole standoff affecting stope performance to differing degrees. This 
indicates that borehole layout and blasting design should be investigated for stope performance optimisation.

For this case study, borehole orientation, dip and dip direction, faults and distance to convex hull are not presented in the results as they are not critical factors for the HW performance. The HW geometry already represents a simplified shape and therefore, the distance to convex hull does not apply in this case. It is, however, an interesting parameter for the side walls as the geometry is more complex due to adjacent stope mining. The borehole orientation for the HW are mostly parallel due to the face being built on the drill ring, therefore there is not enough variation in the orientation to analyse this parameter for the HW.

This study should be considered only as a first pass investigation into a mine site's database. Many more in-depth investigations are possible with the newly developed tools and additional site-specific data relevant to the factors which control stope performance.

\section{Conclusion}

A novel and innovative tool was successfully developed to facilitate and improve the stope reconciliation process by enabling stope performances to be quantified with respect to three progressively finer levels of detail, based on entire stopes, individual stope faces, and octree blocks. The tools coded in the widely used Australian Centre for Geomechanics software, mXrap, are user-friendly and will not only be time saving to engineers at mine sites but will also enable much more powerful diagnostic analyses to uncover the root causes of overbreak and underbreak.

The octree analysis that was developed is a new and innovative technique that subdivides stope volumes into small blocks. This enabled new types of investigation to understand the effect on stope surface stability of a range of factors including blasthole standoff distance, orientation and energy, ERF, distance to development, distance and orientation to faults, and distance to convex hull. Analysis on a per octree basis allows for stope performance to be assessed at a resolution where the variation of performance and influencing factors can be captured (usually $<1 \mathrm{~m}^{2}$ ).

Stope performances from the case study has been quantified and analysed based on individual stope faces, and octree blocks. The use of the novel technique of octree analysis lead to the following conclusions.

Octree-level resolution analysis was critical to identifying localised effects of blasting on stope performance and illustrating the significance of how blast design as a major driver for overbreak and underbreak for this case study.

The use of ERF is very informative and consistently correlates with the location of overbreak and underbreak.

\section{Acknowledgement}

The authors thank the sponsor for permission to use their data in this paper. This research would not be possible without the 7 industry sponsors of this project, MRIWA and the ongoing collaboration from mine sites personnel. The sponsors were: Agnico Eagle Mines Ltd, LaRonde Mine, BHP, Olympic Dam Mine, Glencore Mount Isa Mines, Gold Fields Australia Pty Ltd, Granny Smith Mine, Hecla Limited, Casa Berardi Mine, IAMGOLD Corporation, Westwood Mine, MMG Limited, Dugald River Mine, and Minerals Research Institute of Western Australia (MRIWA). We gratefully acknowledge both the corporate and individual support. 


\section{Appendix Local characterisation of stope design parameters for per octree analysis}

\begin{tabular}{|c|c|c|c|}
\hline Parameter & Concept & Interpretation & Example \\
\hline $\begin{array}{l}\text { Borehole } \\
\text { standoff } \\
\text { distance }\end{array}$ & $\begin{array}{l}\text { Distance from an octree } \\
\text { block to nearest designed } \\
\text { borehole }\end{array}$ & $\begin{array}{l}\text { Blast-induced } \\
\text { damage }\end{array}$ & \\
\hline $\begin{array}{l}\text { Borehole } \\
\text { orientation }\end{array}$ & $\begin{array}{l}\text { Shortest angle between an } \\
\text { octree's design normal } \\
\text { vector and the borehole. } \\
\text { Convention: } 90^{\circ}=\text { Toeing, } \\
0^{\circ}=\text { Parallel }\end{array}$ & $\begin{array}{l}\text { Blast-induced } \\
\text { damage }\end{array}$ & \\
\hline $\begin{array}{l}\text { Proxy for } \\
\text { blast energy }\end{array}$ & $\begin{array}{l}\quad \begin{array}{l}\text { Blast energy } \\
n\end{array} \\
\quad \approx \sum_{0}^{\mathrm{m}} \frac{\mathrm{L}}{\max (0.5, D)^{2}} \\
\text { where: } \\
\mathrm{L}=\text { Length of hole } \\
\mathrm{D}=\text { Distance to hole } \\
\text { Max. distance of } 0.5 \mathrm{~m} \text { to } \\
\text { account for stemming near } \\
\text { collars }\end{array}$ & $\begin{array}{l}\text { Blast-induced } \\
\text { damage }\end{array}$ & \\
\hline $\begin{array}{l}\text { Dip of the } \\
\text { design } \\
\text { surface }\end{array}$ & $\begin{array}{l}\text { The dip calculated from the } \\
\text { normal vector associated } \\
\text { with the octree block }\end{array}$ & $\begin{array}{l}\text { Influence of } \\
\text { gravity }\end{array}$ & \\
\hline
\end{tabular}




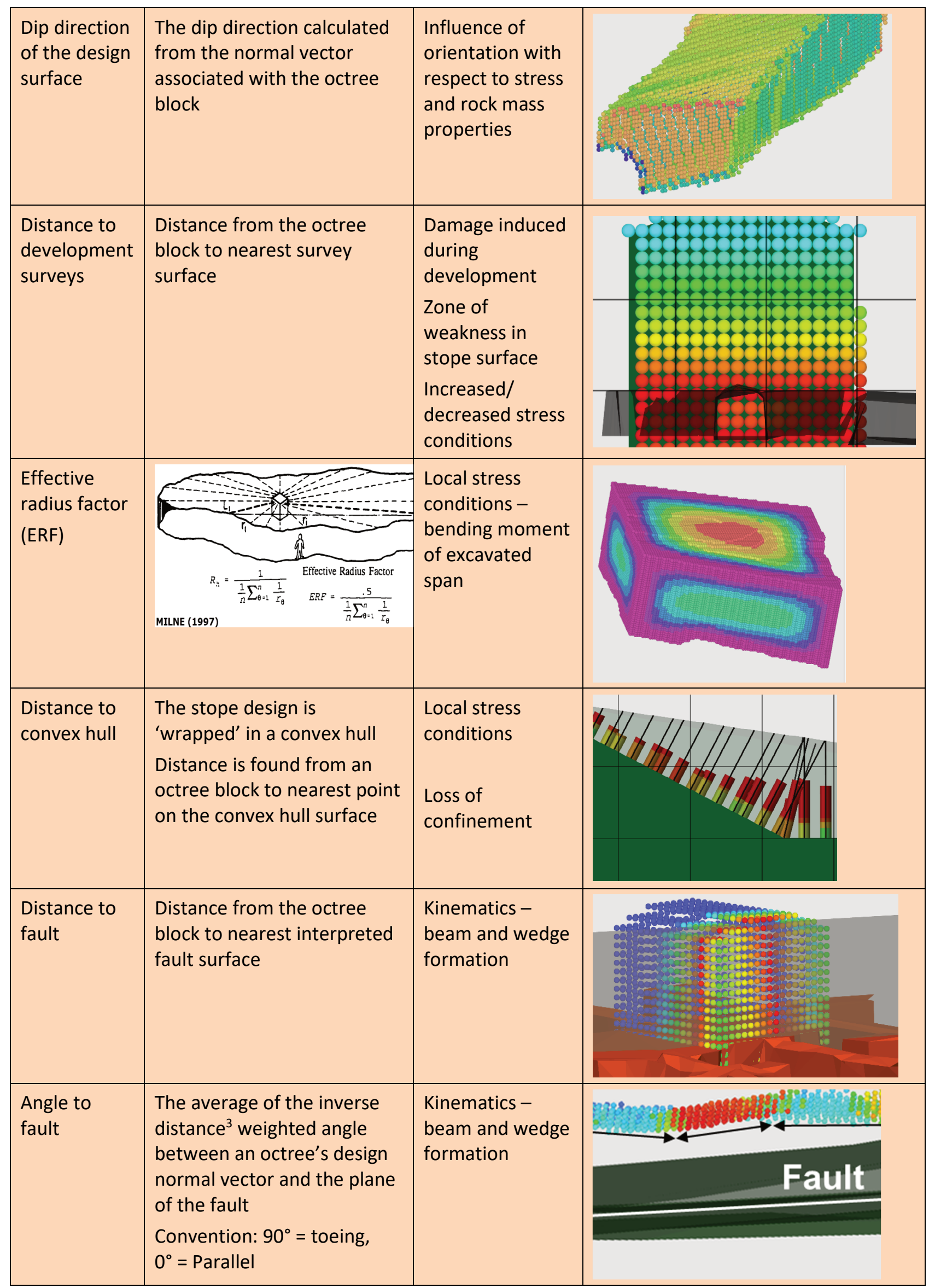




\section{References}

Clark, L 1998, Minimizing dilution in open stope mining with a focus on stope design and narrow vein longhole blasting, MSc thesis, University of British Columbia, Vancouver.

Mathews, KE, Hoek, E, Wyllie, DC \& Stewart, SBV 1981, Prediction of stable excavation spans for mining at depth below 1,000 $m$ in hard rock mines, Report to Canada Centre for Mining and Energy Technology, Ottawa.

Miller, F, Potvin, Y \& Jacob, D 1992, 'Laser measurement of open stope dilution', CIM Bulletin, vol. 85, pp. 96-102.

Potvin, Y, Grant, D, Mungur, G, Wesseloo, J \& Kim, Y 2016,'Practical Stope Reconciliation in Large-scale Operations Part 2, Olympic Dam, South Australia', in C Carr \& G Chitomobo (eds), Proceedings of the Seventh International Conference \& Exhibition on Mass Mining, Australasian Institute of Mining and Metallurgy, Melbourne, pp. 501-509. 
